\title{
SOCIAL FREEZING E (IM) POSSIBILIDADE DE UTILIZAÇÃO DE ÓVULOS CONGELADOS PELOS ASCENDENTES
}

\author{
SOCIAL FREEZING AND (IM) POSSIBILITY OF USING FREEZED EGGS BY \\ ASCENDANTS
}

Mariana Saudino

\section{RESUMO}

A técnica denominada social freezing vem sendo cada dia mais utilizada por mulheres que desejam postergar a maternidade. Considerando os inúmeros avanços da sociedade e a consequente emancipação da mulher, pretendese analisar a reprodução humana assistida em relação à autonomia existencial e aos desdobramentos daí advindos.

Palavras-chaves: Social freezing; reprodução humana assistida; autonomia existencial.

\begin{abstract}
The technique called social freezing has been increasingly used by women who want to postpone motherhood. Considering the numerous advances in society and the consequent autonomy of women, we intend to analyze the assisted human reproduction in relation to the existential autonomy and the consequences that stem from them.
\end{abstract}

Keywords: Social freezing; assisted human reproduction; existential autonomy.

\section{INTRODUÇÃO}

O presente estudo apresenta considerações sobre as técnicas de reprodução assistida, mediante o congelamento de gametas, que permite a mulher postergar a gestação. Diante dos avanços que impactaram a (re)construção do Direito de família, a constitucionalização das relações privadas e a aceitação do afeto como princípio propulsor capaz de solucionar questões, serão vetores que auxiliarão na compreensão do tema proposto.

Destaca-se o quão facilitadoras do sonho da maternidade são essas técnicas, seja proporcionando a concretização da parentalidade ou uma produção independente. Podendo, assim como as técnicas de reprodução assistida (RA), ser um facilitador, quebrando paradigmas, inclusive, em relação à falta de legislação pertinente sobre o tema, pois a ausência da norma faz com que regulamentos administrativos, voltados para classe médica, sejam os únicos instrumentos a auxiliarem a interpretação de conflitos de interesse. 
Ainda quanto às regulamentações, a Resolução 2.168/2017, ainda é falha e, por isso, não consegue alcançar todos possíveis dilemas. Tratando inclusive do termo de consentimento, o qual deve ser analisado entre as partes, demonstrando o quanto deve prevalecer a vontade do indivíduo naquele momento e não, simplesmente, ser imposto, pois prevalece nesta seara a mínima intervenção do Estado nas constituições familiares.

O trabalho busca compreender a manifestação da vontade da mulher solteira, que recorre ao congelamento de óvulos ou "social freenzing", a qual sempre demonstrou seu desejo de ser mãe, que fez todo o procedimento clínico correto, mas que falece durante este período. Diante do óbito, o objeto de estudo será compreender se é ou não possível a reprodução assistida post mortem, que é considerada pelas Resoluções do Conselho Federal de Medicina, desde que previamente determinada no termo de consentimento.

Neste cenário, teriam os ascendentes, que sabem do procedimento feito pela filha falecida e do seu desejo de ser mãe, direito de pleitearem a continuidade desse planejamento familiar da descendente, considerando os princípios da mínima intervenção do Estado, da autonomia privada, do livre planejamento familiar e da afetividade.

Dessa forma, o presente estudo propõe a seguinte problematização: a afetividade poderia ser utilizada com verdadeiro vetor normativo apto a justificar o desejo dos ascendentes de darem continuidade à manifestação do planejamento familiar da filha falecida?

\section{BREVE RESUMO SOBRE O DIREITO DE FAMÍLIA ATUAL}

Historicamente, o Direito de família, pode ser dividido em três marcos temporais, que demonstraram a evolução da matéria, a saber: (i) até 1970 quando a família era exclusivamente matrimonial e indissolúvel, com forte hierarquização, devido ao patriarcalismo dominante; (ii) meados dos anos 70 (1970), início da tramitação do Código Civil em 1975 e, em 1977, temos a Emenda Constitucional 9/1977, que introduz o divórcio no país, após três anos de separação, ou seja, ocorre a dissolução daquilo que antes era indissolúvel; (iii) em 1988 com a Nova Constituição, um novo olhar é lançado ao Direito Civil, permitindo a despatrimonialização da matéria, por meio dos princípios e ideais defendidos na Constituição que permeiam o direito e promovem maior ênfase no indivíduo, ampliando e valorizando a autonomia da vontade, bem como, por fim, atingindo de forma positiva à família, agora constitucionalizada.

Após a Constituição de 1988, uma nova era no Direito de família se inicia e possibilita a formação de diversos arranjos familiares, conforme o artigo 226 e seus parágrafos, que 
garantem como família não só a matrimonial, como a monoparental e até mesmo aquelas formadas pelo afeto. Desta forma, o Estado permite que o indivíduo faça suas escolhas, devendo assegurar os direitos e proteger os integrantes de quaisquer estruturas familiares, o que significa a garantia constitucional do planejamento familiar.

Sob tal perspectiva, é possível entender que a proteção da pessoa humana pode ser “considerado ao mesmo tempo direito e dever fundamental, uma vez que este impõe limites à sociedade civil em geral e aos poderes estatais e aos particulares, de forma a garantir a plena efetivação de direitos e deveres essenciais à própria condição humana" ${ }^{1}$.

De acordo com Guilherme Calmon Nogueira da Gama

O exame mais aprofundado do próprio dispositivo, aliado a outras normas constitucionais - como, por exemplo, a igualdade entre homem e mulher em direitos e em deveres - , permite a conclusão de que o Constituinte disse menos do que queria, provavelmente por ter sido induzido em equívoco diante da tradução do termo parental responsibility, que possui outra significação no âmbito do direito inglês", diante do que, "sem o cuidado que se deveria ter no transplante jurídico da noção inglesa para o direito brasileiro, o Constituinte empregou o termo paternidade responsável quando, na realidade, o sentido é o da parentalidade responsável, referindo-se a expressão, logo, não apenas ao homem, mas também à mulher.

Observa-se, assim, que os princípios constitucionais ${ }^{3}$ do direito de família têm um importante papel para garantir que os direitos e deveres dos núcleos familiares sejam efetivados diante dos contemporâneos paradigmas pelos quais se reconhece a superação do modelo familiar tradicional.

Com a constitucionalização do direito de família, os princípios ganham novo sentido.

Considerando a tutela da pessoa ${ }^{4}$ humana como princípio maior, abarcando a igualdade, a

1 DUQUE, Bruna Lyra. LEITE, Letícia Durval. Dever fundamental de afeto e alienação parental. Revista de Direito de Família e das Sucessões, v. 3, p. 15-31, 2016.

2 GAMA, Guilherme Calmon Nogueira da. Princípios constitucionais de direito de família: guarda compartilhada à luz da lei n.o 11.698/08 - família, criança, adolescente e idoso. São Paulo: Atlas, 2008. p. 77 e 78 .

3 Conforme sustenta Luiz Edson Fachin: "A família, não obstante se submeta à legislação infraconstitucional, tem o centro irradiador da sua regulação no Texto Constitucional. E é a partir daí que se fala na incidência dos princípios constitucionais não apenas nas relações familiares, mas em todas as relações interprivadas; não apenas no campo dos direitos fundamentais, como queira ler o constitucionalismo, mas em todas as dimensões das relações privadas: nos contratos, na família, na propriedade”. FACHIN, Luiz Edson. Princípios Constitucionais do Direito de Família brasileiro contemporâneo. In: BASTOS, Ferreira Eliene; DIAS, Maria Berenice (Coords.). A família além dos mitos. Belo Horizonte: Del Rey, 2008. p. 123.

4 "Com isso, parece ficar claro que a ligação entre a lei, os direitos reais, os direitos pessoais e o contrato, se explicita nesta medida e, obviamente, também se submete a alguns novos parâmetros que são congruentes com os valores desta transição entre os séculos. Neles, ao centro, está a pessoa e a realização de suas necessidades fundamentais, pessoais e coletivas. Daqui se extrai a inviabilidade de articular, com segurança desejável, um porto de atracagem, eis que o tempo sugere, nesse espaço contemporâneo, constantes renovações de significantes e de significados. Essa contínua transformação é compreensível na axiologia e na ideologia." FACHIN, Luiz Edson. Teoria crítica do direito civil. Rio de Janeiro: Renovar, 2003. p. 231. 
solidariedade e a afetividade ${ }^{5}$, o estudo apresenta os mais importantes vetores principiológicos para analisar a reprodução assistida e o social freezing.

Para Bruna Lyra Duque e Letícia Leite ${ }^{6}$, o dever de afeto encontra o seu fundamento constitucional na proteção da pessoa humana. Este princípio, como valor básico do Estado Democrático de Direito, estabelece-se na sociedade como uma forma de proteger o indivíduo de quaisquer ataques, tanto do Estado e da sociedade, como de uma outra pessoa, buscando tutelar a integridade física, psíquica e moral dos indivíduos.

Quanto ao princípio da afetividade, Giselle Groeninga ${ }^{7}$ leciona que:

O papel dado à subjetividade e à afetividade tem sido crescente no Direito de Família, que não mais pode excluir de suas considerações a qualidade dos vínculos existentes entre os membros de uma família, de forma que possa buscar a necessária objetividade na subjetividade inerente às relações. Cada vez mais se dá importância ao afeto nas considerações das relações familiares; aliás, um outro princípio do Direito de Família é o da afetividade.

Considera-se, então, a afetividade um divisor de águas na história do direito de família, sendo recorrente a sua presença em decisões judiciais. As famílias podem se formar pelo desejo, pelo afeto e depois com o reconhecimento da filiação e maternidade e/ou paternidade socioafetivas $^{8}$, o que também repercute na igualdade entre os filhos, na união estável, na união homoafetiva.

Observa-se que "se o liame que liga um pai a seu filho é um dado, a paternidade pode exigir mais que apenas laços de sangue. Afirma-se aí a paternidade socioafetiva que se capta juridicamente na expressão da posse de estado de filho". Ademais, não existem regras quando se projeta as condutas afetivas nas relações familiares. "A verdade sociológica da filiação se constrói ${ }^{9} . "$

5 Explica Ricardo Calderón que: “Apesar de muitas decisões judiciais não citarem explicitamente seu reconhecimento como princípio, muitas delas deixam transparecer o caráter principiológico da afetividade, eis que sua incidência não é pontual e específica - como corrente no trato de regras, mas é possível notar sua utilização como verdadeiro mandamento de otimização, que pode ter maior ou menor amplitude de acordo com cada situação fática em apreço. $\mathrm{O}$ acolhimento da afetividade pela jurisprudência brasileira permite perceber sua aceitação como princípio implícito do direito de família, que se irradia nas diversas relações familiares, sempre que presente em determinada situação subjetiva". CALDERÓN, Ricardo. Princípio da afetividade no direito de família. Rio de Janeiro: Forense, 2017. p. 100.

6 DUQUE, Bruna Lyra. LEITE, Letícia Durval. A alienação parental sob a perspectiva do dever fundamental de afeto e a psicologia, Revista de artigos da $1^{\text {a }}$ Jornada Científica Científica do Fórum de Assistentes Sociais e Psicólogos do Poder Judiciário do ES, Vitória, p. 293-298, 2015.

7 GROENINGA, Giselle Câmara. Direito de Família. In: BARBOSA, Águida Arruda; VIEIRA, Claudia Stein (Orgs.). Direito Civil. São Paulo: Revista dos Tribunais, 2008. v. 7, p. 28.

8 "Cada vez mais se reconhece que, em nossa cultura, é a ligação socioafetiva que se tem com a criança que se mostra verdadeiramente importante na estruturação da personalidade e no desenvolvimento do sujeito, sendo por isso essa ligação a grande merecedora de toda a valorização sociojurídica". PAULO, Beatrice Marinho. Ser Mãe nas Novas Configurações Familiares: a Maternidade Psicoafetiva. Revista Brasileira de Direito das Famílias e Sucessões, Porto Alegre, Magister; Belo Horizonte, IBDFAM, v. 9, abr./maio 2009, p. 57.

9 FACHIN, Luiz Edson. Da Paternidade - Relação Biológica e Afetiva. Belo Horizonte: Del Rey, 1996. p. 3637. 
O princípio jurídico da afetividade ganha espaço e aplicabilidade para reconhecer como pessoas integrantes da mesma família, indivíduos, que nos moldes tradicionais não seriam considerados como membros de tal.

Reforçar a necessidade do cumprimento dos deveres na seara familiar (aí incluindo a afetividade como conduta) é, sem dúvida alguma, uma excelente mudança para a sociedade ${ }^{10}$.

O perfil consensual e o sentimento de afeição devem ser considerados, segundo Guilherme Calmon Nogueira da Gama"11, como os "alicerces das famílias jurídicas, resgatando a afetividade nas relações privadas mais próximas e íntimas".Afetividade é uma conduta que vai além do afeto, pois se materializa no respeito, consideração, cuidado, assistência moral, quebrando paradigmas considerados imutáveis, como diversos casos encontrados na jurisprudência. Por exemplo, no caso que prevaleceu o afeto em adoção post mortem ${ }^{12}$ e a avó ficou com a guarda do menor.

Com a Constituição de 1988, foi instituído o princípio do livre planejamento familiar, conforme disposto no artigo 226 , parágrafo $7^{\circ}, \mathrm{CR} / 88^{13}$, fundamentado pelo princípio da tutela da pessoa humana e da paternidade responsável. Além do íntimo liame com os princípios da solidariedade familiar e da autonomia privada, possibilitando ao indivíduo ser titular das suas próprias escolhas e viver harmonicamente e cooperativamente em família.

10 DUQUE, Bruna Lyra. SANTOS, Danilo Ribeiro Silva dos. Novas perspectivas das ações de família: a cultura do litígio perde a sua força. In: $2^{\mathrm{a}}$ Jornada Científica do Fórum de Assistentes Sociais e Psicólogos

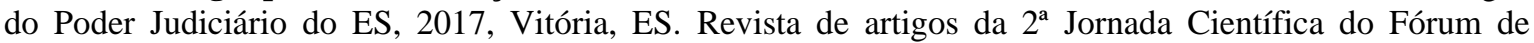
Assistentes Sociais e Psicólogos do Poder Judiciário do ES, Vitória, p. 254-262, 2017.

11 GAMA, Guilherme Calmon Nogueira da. Princípios constitucionais de direito de família: guarda compartilhada à luz da lei n.o 11.698/08 - família, criança, adolescente e idoso. Op. cit. p. 121.

12 RECURSO ESPECIAL. NÃO INDICAÇÃO DA ALÍNEA "A" DO PERMISSIVO CONSTITUCIONAL. FUNDAMENTAÇÃO QUE PERMITE A COMPREENSÃO DA CONTROVÉRSIA. ADOÇÃO PÓSTUMA. POSSIBILIDADE. GUARDA DE MENOR. PEDIDO DE AUTORIA DA AVÓ. FALECIMENTO DA AUTORA NO CURSO DO PROCESSO. Intenção inequívoca de obtenção da guarda. Laço de afetividade entre os envolvidos. Possibilidade do deferimento. Concessão de benefício previdenciário. Efeito da Concessão. (...)

2. A Lei n. $8.069 / 1990$, em seu art. $42, \S 6^{\circ}$, estabelece que "a adoção poderá ser deferida ao adotante que, após inequívoca manifestação de vontade, vier a falecer no curso do procedimento, antes de prolatada a sentença". 3. Em situações excepcionais, em que demonstrada a inequívoca vontade em adotar, diante da longa relação de afetividade, pode ser deferida adoção póstuma ainda que o adotante venha a falecer antes de iniciado o processo de adoção. (...) 7. No caso dos autos, no interesse maior da criança, impõe-se o reconhecimento da guarda à "avó", de quem a criança recebia afeto desde o nascimento e que promovia a concretização de todos os demais cuidados básicos à sua existência, sendo o fim precípuo do processo garantir vida com dignidade à menor especial. (...)10. Recurso especial provido para o deferimento do pedido de guarda póstuma. (REsp 1677903/SP, Rel. Ministro LUIS FELIPE SALOMÃO, QUARTA TURMA, julgado em 28/11/2017, DJe 07/03/2018). Disponível em: https://ww2.stj.jus.br/processo/revista/documento/mediado/?componente=ITA\&sequencial=1661779\&num_r egistro $=201601742190 \&$ data $=20180307 \&$ formato $=P D F$. Acesso em: 08 de agosto de 2019.

$13 \$ 7^{\circ}$ Fundado nos princípios da dignidade da pessoa humana e da paternidade responsável, o planejamento familiar é livre decisão do casal, competindo ao Estado propiciar recursos educacionais e científicos para o exercício desse direito, vedada qualquer forma coercitiva por parte de instituições oficiais ou privadas. 
Tomando como base o artigo $227^{14}$ da Constituição Federal, parece importante avaliar como o Estado cumpre os seus deveres fundamentais. Sabe-se que é dever da família, da sociedade e do Estado, cuidar das crianças e adolescentes. Quando a autonomia privada e a visão meramente patrimonialista são consideradas como critérios valorativos mais relevantes, nas relações familiaristas, bem como as suas interpretações afrontam princípios, como o melhor interesse do menor, o direito se afasta da preservação da pessoa humana.

Deve-se adotar a aplicação sopesada com outros princípios e mitigar a intervenção estatal nas situações de interferência ao planejamento familiar. Resta claro que autonomia de vontade conjugada com princípio da autonomia privada é diferente da capacidade privado do indivíduo de estabelecer acordos, ou seja, são questões distintas, pois a autonomia relaciona-se ao exercício pleno da liberdade, originado do princípio da dignidade da pessoa humana e não somente à capacidade de firmar contratos ${ }^{15}$.

Como esclarece Bruna Lyra Duque ${ }^{16}$ :

O grau de proteção constitucional conferido à pessoa humana vai depender da sua posição dentro de uma equilibrada escala protetiva: quanto mais se aproximar da esfera das opções exclusivamente existenciais, maior será o nível de defesa constitucional do indivíduo.

Atualmente, o Estado só deve intervir nas relações familiares, em situações excepcionais, tais como maus tratos, perda e suspensão do poder familiar, violência doméstica e outras questões que dependam de seu posicionamento.

O direito de família mais humano se faz com a análise desse importante ramo do direito a partir do "ângulo dos direitos humanos, cujas bases e ingredientes estão, também, diretamente relacionados à noção de cidadania ${ }^{17}$ ".

Devido ao grau de relevância que a família possui para a vida de suas crianças e seus adolescentes, "torna-se indispensável que todos os membros consigam realizar, de forma plena, suas respectivas responsabilidades para um desenvolvimento sustentável do ambiente familiar $^{18 \%}$.

14 Art. 227. É dever da família, da sociedade e do Estado assegurar à criança, ao adolescente e ao jovem, com absoluta prioridade, o direito à vida, à saúde, à alimentação, à educação, ao lazer, à profissionalização, à cultura, à dignidade, ao respeito, à liberdade e à convivência familiar e comunitária, além de colocá-los a salvo de toda forma de negligência, discriminação, exploração, violência, crueldade e opressão.

15 MADALENO, Rolf. Direito de Família. 9a Ed. Rio de Janeiro: Forense, 2019. p. 93.

16 DUQUE, Bruna Lyra. Adoção, perda de uma chance e abandono estatal. Revista de Direito de Família e das Sucessões. São Paulo: RT, a. 3, n. 8, p. 67-82, abr./mai. 2016.

17 PEREIRA, Rodrigo da Cunha. Família, direitos humanos, psicanálise e inclusão social. Revista do Ministério Público do Rio Grande do Sul, n. 58, maio/ago., p. 195-201, 2006.

18 DUQUE, Bruna Lyra; LEITE, Letícia Durval. Dever fundamental de afeto e alienação parental. Revista de Direito de Família e das Sucessões, v. 3, p. 15-31, 2016. 
A intervenção estatal é uma medida excepcional, restando consagrado o princípio da mínima intervenção, conforme determinação expressa no Código Civil, no art. 1.513, a saber: "é defeso a qualquer pessoa de direito público ou direito privado interferir na comunhão de vida instituída pela família”.

\title{
3. AUTONOMIA DA VONTADE E AUTONOMIA DA MULHER
}

Durante toda a história da humanidade, os varões sempre exerceram controle sobre as ações femininas, principalmente com a capacidade de exercício da autonomia da vontade.

Para Rolf Madaleno, tem-se que:

\begin{abstract}
A liberdade e maior autonomia da mulher com o abandono da versão conjugal do marido provedor, em uma relação moldada no passado, na ideia de dominação da esposa pelo homem, sobremodo em função da sua dependência econômica, na qual a mulher terminava arrastando seus filhos, sujeitando-se às alianças de sobrevivência e infelicidade, deixaram de habitar as angústias femininas (...) não mais intencionam ver a si e seus filhos encerrados em uma relação de autoridade e de coação ${ }^{19}$.
\end{abstract}

Vislumbra-se que a autonomia pressupõe um sujeito capaz de se afirmar perante o outro como ator apto a fundamentar verbalmente suas ações, intenções, desejos e necessidades ${ }^{20}$.

De acordo com Bruna Lyra Duque ${ }^{21}$, o "sujeito de direito é o protagonista da relação jurídica e será sempre tutelado por direitos fundamentais". Assim, pode-se dizer que cada indivíduo por estar inserido na sociedade "deve agir em busca de uma perspectiva solidarista, (...) pois, focando-se na autonomia da vontade, não pode se afastar de noções de cooperação com o outro".

Com a evolução da sociedade e consequente mudança do direito e legislação, a mulher torna-se independente e não mais aquela que cuida apenas de tarefas domésticas e tem por função procriar. A mulher chega ao mercado de trabalho, conquista sua independência financeira.

Por mais que tenham alcançado essa possibilidade de liberdade de escolha, muitas mulheres carregam o desejo de serem mães e por uma série de fatores, principalmente, profissionais, precisam postergar a maternidade, a qual exige sua dedicação integral.

Como esclarece Zygmunt Bauman ${ }^{22}$ :

19 MADALENO, Rolf. Direito de Família. Op. cit. p. 37.

20 REGO, Valquiria Leão; PINZANI, Alessandro. Vozes do Bolsa Família: autonomia, dinheiro e cidadania. $2^{\mathrm{a}}$ Ed. São Paulo: Unesp, 2014. p. 41.

21 DUQUE, Bruna Lyra. Causa do contrato: entre direitos e deveres. Belo Horizonte: Conhecimento, 2018. p. 55.

22 BAUMAN, Zygmunt. Modernidade Líquida. Trad. Plínio Dentzien. Rio de Janeiro: Zahar, 2001. p. 14. 
"Hoje, os padrões e configurações não são mais 'dados', e menos ainda ' autoevidentes'; eles são muitos, chocando-se entre si e contradizendo-se em seus comandos conflitantes, de tal forma que todos e cada um foram desprovidos de boa parte de seus poderes de coercitivamente compelir e restringir."

Assim, se valendo de mais um preceito constitucional, a dignidade com os direitos da personalidade, passa a ter autonomia para decidir sobre a hora e a forma de gerar uma criança. “Assim, procedendo, abrir-se-á caminho para que o Direito Civil contemporâneo não seja mero alinhamento com estruturas arcaicas retocadas, contidas em códigos de antemão determinados, de tipo conceitual, geral e abstrato ${ }^{23}$ ".

\section{SOCIAL FREEZING - TÉCNICA DE REPRODUÇÃO ASSISTIDA}

Entende-se como parentesco, para uma doutrina mais conservadora, "a relação que vincula entre si pessoas que descendem umas das outras, ou de autor comum, que aproxima cada um dos cônjuges dos parentes do outro ou que se estabelece por fictio iuris, entre o adotado e o adotante ${ }^{24 "}$.

Ocorre que, hodiernamente, deve ser considerado o conceito de parentesco de forma mais ampla não tendo mais lugar a noção de parentesco que se faz apenas proveniente da relação entre pessoas a partir da descendência.

O parentesco, no mundo contemporâneo, deve ser compreendido "como o vínculo, com diferentes origens, que atrela determinadas pessoas, implicando em efeitos juridicos diversos entre as pessoas envolvidas ${ }^{25}$ ",

Considerando o tempo das famílias e as múltiplas possibilidades de formação, aliada a evolução científica e necessidades sociais, chega-se ao tempo da reprodução assistida, importante instrumento da ciência e medicina, que trouxe esperança àqueles que não podem ter filhos, seja por razões biológicas ou não, como na hipótese desse estudo, onde por razões profissionais a mulher busca uma das técnicas para postergar a gravidez.

FACHIN, Luiz Edson. Teoria crítica do direito civil. Op. cit. p. 46.

24 PONTES DE MIRANDA, Francisco Cavalcanti. Tratado de Direito de Família. Campinas: Bookseller, 2003. p. 23.

25 FARIAS, Cristiano Chaves de. ROSENVALD, Nelson. Curso de Direito Civil: Famílias. Salvador: JusPodivm, 2019. p. 557. 
A família é o núcleo básico da sociedade. Sem a família não é possível falar em plenitude de qualquer organização social ou jurídica. "É a família que nos estrutura como sujeitos e encontramos algum amparo para o nosso desamparo estrutural ${ }^{26 "}$.

Diversas são as técnicas de reprodução assistida ${ }^{27}$, as quais tem início com o nascimento do primeiro bebê de proveta, na Inglaterra em 1978 e, a partir daí, nota-se constante evolução e aperfeiçoamento, o que as popularizou, estimando-se que mais de 8 milhões ${ }^{28}$ de pessoas são fruto de reprodução assistida no planeta.

Neste sentido, esclarecem Débora Gozzo e Wilson Ligiera ${ }^{29}$ :

A Constituição Federal de 1988 assegura aos casais o direito do livre exercício do planejamento familiar, o que envolve decidir se desejam ou não ter filhos, quantos filhos desejam ter, proporcionado pelo Estado o conjunto de informações necessárias para a tomada de uma decisão consciente e responsável, bem como a faculdade de recorrerem ao auxílio da medicina reprodutiva para a utilização de técnicas de reprodução humana assistida que viabilizem a gravidez.

Dentre essas técnicas alternativas à reprodução natural, destaca-se a social freenzing, comumente chamada de congelamento de óvulos ou de parte do tecido ovariano da mulher, a qual pode decidir pelo procedimento e assim postergar a maternidade.

Heloisa Helena Barboza ${ }^{30}$ esclarece que a técnica de utilização do útero apresenta “características próprias: não se trata de transplante, nem de pesquisa, sequer, a rigor, de tratamento, não implicando mutilação. Não há separação do corpo, mas, indiscutivelmente, existe uma forma de disposição do órgão".

No entanto, tal procedimento deve ser realizado no período da idade ideal, preferencialmente até os 35 anos de idade ${ }^{31}$, ou seja, geralmente idade do ápice profissional da

26 PEREIRA, Rodrigo da Cunha. Família, direitos humanos, psicanálise e inclusão social. Revista do Ministério Público do Rio Grande do Sul, n. 58, maio/ago., p. 195-201, 2006.

27 (...) É a fertilização ou inseminação medicamente assistida. São os procedimentos médicos utilizados para suprir fatores biológicos, médico ou psíquicos que impedem a união permanente dos gametas masculino e feminino, gerando a esterilidade ou a incapacidade para procriar.

28 ANSA. Reprodução Assistida já Gerou Mais de 8 Milhões de Bebês. Disponível em <https://istoe.com.br/reproducao-assistida-ja-gerou-mais-de-8-milhoes-de-bebes/>. Acesso em: 17 de maio de 2019.

29 GOZZO, Débora; LIGIERA, Wilson Ricardo. Maternidade de substituição e a lacuna legal: questionamentos. Civilistica.com. Rio de Janeiro, a. 5, n. 1, 2016. Disponível em: <http://civilistica.com/maternidade-de-substituicao-e-a-lacuna-legal-questionamentos/>. Acesso em: $17 \mathrm{de}$ maio de 2019.

30 BARBOZA, Heloisa Helena. A filiação em face da inseminação artificial e da fertilização "in vitro". Rio de Janeiro: Renovar, 1993. p. 32.

31 SBRA. Congelamento de Óvulos é Mais Eficaz Em Mulheres de Até 35 Anos. Disponível em < https://sbra.com.br/noticias/congelamento-de-ovulos-e-mais-eficaz-em-mulheres-de-ate-35-anos/>. Acesso em 18 de maio de 2019. 
mulher. No Brasil, a busca pela técnica triplicou nos últimos anos, conforme dados da ANVISA $^{32}$.

Percebe-se que, seja pressionada por questões profissionais ou por dúvidas quanto uma gestação, o congelamento assegura à mulher a gestação no momento que julgar correto, não sendo prejudicada pelo fator idade, considerando que não há um prazo para armazenagem.

Outrossim, não tendo um parceiro/doador, poderá optar por uma produção independente, e mais uma vez utilizar um meio não natural, no caso a reprodução assistida heteróloga, com a doação de material de um terceiro que dará origem a embrião, posteriormente implantado na mulher que passará a ter uma gestação como qualquer outra.

Contrariando o esperado, a legislação não caminhou conforme a ciência e, desta forma, não há lei específica sobre a temática, mesmo o Código Civil em seu artigo 1.597, inciso III, que aceita à filiação por fecundação artificial homóloga e a Constituição autorizando o livre planejamento familiar.

O Enunciado 129, da I Jornada de Direito Civil ${ }^{33}$, propõe a inclusão do artigo 1.597-A no Código Civil, a saber:

Art. 1.597-A. A maternidade será presumida pela gestação.

Parágrafo único: Nos casos de utilização das técnicas de reprodução assistida, a maternidade será estabelecida em favor daquela que forneceu o material genético, ou que, tendo planejado a gestação, valeu-se da técnica de reprodução assistida heteróloga.

Ao comentar o Enunciado, assim se manifestam Cristiano Chaves e Nelson Rosenvald ${ }^{34}$ :

Sob o ponto de vista filiatório, não se pode deixar de notar que, apesar da falta disciplina legal expressa, a gestação em útero alheio implica em relativização presunção mater semper certa est (a mãe é sempre certa, indicada pelo parto), identicamente, a incidência da presunção pater is est (segundo a qual o do filho de uma mulher é o seu marido). Em tais hipóteses, a determinação de será submetida a outros critérios, em especial o cumprimento aos requisitos estabelecidos na Resolução do Conselho Federal de Medicina, devendo ser prestigiada filiação biológica, garantindo-se a quem emprestou material genético o estabelecimento da relação de parentesco.

Nota-se que sob o prismo histórico, o biologismo outrora foi enaltecido como critério para filiação. No entanto, o que hoje se observa é que "houve uma alteração de rumo no discurso

32 ANVISA/ASCON. Reprodução Humana Assistida cresce 18,7\% em 2018. Disponível em <http://portal.anvisa.gov.br/rss/-/asset_publisher/Zk4q6UQCj9Pn/content/id/5563133>. Acesso em: 17 de maio de 2019.

33 I Jornada de Direito Civil, promovida pelo Centro de Estudos Judiciários (CEJ) do Conselho da Justiça Federal (CJF), nos dias. 12 e 13 de setembro de 2002, Brasília - DF. Disponível em: <http://www.cjf.jus.br/cjf/CEJCoedi/jornadas-cej/enunciados-aprovados-da-i-iii-iv-e-v-jornada-de-direitocivil/compilacaoenunciadosaprovados1-3-4jornadadircivilnum.pdf > . Acesso em: 17 de maio de 2019.

34 FARIAS, Cristiano Chaves de. ROSENVALD, Nelson. Curso de Direito Civil: Famílias. Salvador: JusPodivm, 2019. p. 595. 
jurídico, que passou a não ser unívoco na defesa estrita da adoção do critério biológico na fixação da parentalidade, visto que a complexidade fática não indicava tal medida ${ }^{35}$ ”.

Para Rodrigo da Cunha Pereira ${ }^{36}$ :

Para que um filho verdadeiramente se torne filho, ele deve ser adotado pelos pais, tendo ou não vínculos de sangue que os vinculem. A filiação biológica não é nenhuma garantia da experiência da paternidade, da maternidade ou da verdadeira filiação. Portanto, é insuficiente a verdade biológica, pois a filiação é uma construção que abrange muito mais do que uma semelhança entre os DNA. [...] A presença do pai ou da mãe biológicos não é nenhuma garantia de que a pessoa se estruturará como sujeito.

Fato que faz com que regramentos administrativos sejam determinantes no desenrolar dos procedimentos e utilizados como critérios para as decisões judiciais. Sobre esses regramentos, regula a matéria a Resolução $n^{\circ}$ 2.121/2015 do Conselho Federal de Medicina e a Resolução no 2.168/2017 do mesmo órgão.

Sobre elas passa-se a saber: (i) autorizam a utilização de técnicas de RA por pessoas solteiras e em relações homoafetivas; (ii) a completa ciência sobre o procedimento e o livre consentimento; (iii) que no caso de criopreservação ${ }^{37}$, os pacientes devem expressar sua vontade, por escrito, sobre o que deverá ser feito em caso de divórcio ou dissolução da união estável, doenças graves ou falecimento de um deles ou de ambos, e quando desejam doá-los, ou seja, apesar de tratarem da possibilidade da utilização de técnicas de RA para pessoas solteiras, no momento da criopreservação desconsideram estas; (iv) tratam da gestação por substituição ou cessão temporária do útero, determinando regras condicionantes; (v) permitem a reprodução assistida post mortem condicionada à autorização expressa do falecido, para uso do material criopreservado ${ }^{38}$.

Sendo assim, cruciais ao desenvolvimento da análise é a previsão para reprodução post mortem, a consideração da utilização da técnica por pessoas solteiras e a desconsideração estas quando trata sobre o que deve ser feito com material, em caso de ausência. Ou seja, pontos que comungam com o questionamento inicial do estudo, momento em que o direito de família se faz presente, nas demandas que chegam ao Poder Judiciário, o qual também se apoia em

35 CALDERÓN, Ricardo. Princípio da afetividade no direito de família. Rio de Janeiro: Forense, 2017. p. 71.

36 PEREIRA, Rodrigo da Cunha. Princípios fundamentais norteadores do direito de família. 2. ed. São Paulo: Saraiva, 2012. p. 215-216.

37 Criopreservação ou crioconservação é um processo onde células ou tecidos biológicos são preservados através do congelamento a temperaturas muito baixas.

38 CFM. Resolução $\mathbf{n}^{\mathbf{0}} \mathbf{2 . 1 6 8 / 2 0 1 7}$. Disponível em < http://www.in.gov.br/materia//asset_publisher/Kujrw0TZC2Mb/content/id/19405123/do1-2017-11-10-resolucao-n-2-168-de-21-desetembro-de-2017-19405026> . Acesso em 18 de maio de 2019. 
Provimentos do $\mathrm{CNJ}^{39}$, como por exemplo, os de número 52/2016 e 63/2017, que informam sobre a questão do assento de nascimentos em hipóteses de RA.

Reitera-se que essas Resoluções, criadas para a classe médica, permitem que o Poder Judiciário preencha lacunas legais e, ironicamente, aquelas consideram os avanços da sociedade e do próprio direito, conforme a Resolução $\mathrm{n}^{\circ} 2.168 / 2017^{40}$ trata do reconhecimento da união homoafetiva como unidade familiar, da união estável e da protelação da gravidez pela mulher.

Autorizada por esse instrumento administrativo, assegurada no livre exercício do poder familiar e aliada à autonomia da vontade, a mulher pode congelar seu material genético e, no silêncio da Resolução ou analogicamente ao previsto aos casais, poderia deixar expresso seu desejo sobre o que fazer com o material, já que é sabido que o termo de consentimento das clínicas deve ser debatido e não imposto ao paciente, e nele determinar quem será responsável pelo material nos casos já previstos, mediante a técnica de gestação em útero alheio.

A "surrogate mother" (gestação em útero alheio) é a técnica utilizada pela medicina para permitir que uma paciente possa ter um “embrião - resultante de fecundação com o seu óvulo gestado em útero de pessoa. Enfim, é o procedimento que viabiliza a maternidade a determinadas pessoas às quais a procriação natural não se mostra viável ${ }^{41}$ ”. Em suma, observase que a pessoa que utilizou o próprio útero renunciará a maternidade em favor daquela que cedeu o seu material genético.

Ressalta-se a importante questão aplicável ao direito civil e, igualmente, relevante ao direito de família: o respeito à autodeterminação do indivíduo. A reprodução assistida se projeta na manifestação de vontade daqueles que usam seu material genético. Também há manifestação de vontade na confecção das cláusulas contratuais presentes no termo de consentimento imposto pelas clínicas.

Ao destacar a importância da liberdade de constituição de família, assim se manifesta Rodrigo da Cunha Pereira ${ }^{42}$ :

A partir do momento em que a família se desinstitucionaliza para o Direito - ou seja,
que ela não mais se faz relevante enquanto instituição -, e que a dignidade humana
passa a ser o foco da ordem jurídica, passa-se a valorizar cada membro da família e
não a entidade familiar como instituição. Isto porque passou a vigorar a ampla

39 Provimento 52/2016. Disponível em < https://www.legisweb.com.br/legislacao/?id=317508> . Acesso em 18 de maio de 2019. Provimento 63/2017. Disponível em < http://cnj.jus.br/busca-atos-adm?documento=3380> . Acesso em 18 de maio de 2019.

40 CFM. Resolução $\mathbf{n}^{\mathbf{2}} \mathbf{2 . 1 6 8 / 2 0 1 7}$. Disponível em < http://www.in.gov.br/materia//asset_publisher/Kujrw0TZC2Mb/content/id/19405123/do1-2017-11-10-resolucao-n-2-168-de-21-desetembro-de-2017-19405026>. Acesso em 18 de maio de 2019.

41 FARIAS, Cristiano Chaves de. ROSENVALD, Nelson. Curso de Direito Civil: Famílias. Salvador: JusPodivm, 2019. p. 591.

42 Pereira, Rodrigo da Cunha. Princípios fundamentais norteadores do direito de família. 2. ed. São Paulo: Saraiva, 2012. p. 213-214. 
liberdade de constituir ou de desfazer os laços conjugais, não sendo mais necessário viver junto até que "a morte nos separe". A liberdade de constituição de família tem estreita consonância com o Princípio da Autonomia da Vontade, principalmente nas relações mais íntimas do ser humano, cujo valor supremo é o alcance da felicidade.

Em relação à RA post mortem, casos começam a aparecer pelo mundo, até mesmo porque hoje, em caso de doenças graves, os próprios médicos sugerem o congelamento. Seguem, pois, alguns casos interessantes em relação aos ascendentes usarem o material criopreservado dos filhos, que demonstram a diferença causada devido à lacuna legislativa brasileira.

$\mathrm{Na}$ Índia ${ }^{43}$, um jovem, ao descobrir um grave tumor, foi orientado a preservar seu material antes dos tratamentos de quimioterapia e radioterapia, e seguiu a recomendação deixando responsáveis pelo material sua mãe e irmã, já que era solteiro. Após sua morte, sua mãe viu no material armazenado a chance de ter o filho presente e conforme autorizada, através de métodos artificias e com a ajuda de uma barriga de aluguel, os netos foram gerados.

Já na Inglaterra, em caso semelhante, um jovem congelou seu material e assinou o termo da clínica não autorizando o descarte dos óvulos. Entretanto, sua mãe precisou provar que era desejo de sua filha ser mãe futuramente, o que não foi autorizado nas primeiras decisões, apenas na Corte de Apelação ${ }^{44}$.

Sobre a reprodução post mortem, diz a presidente da Comissão de Bioética do IBDFAM/RS:

(...) a grande maioria dos países veda a inseminação post mortem e que no Brasil não há legislação sobre o assunto. (..) A atual resolução do Conselho Federal de Medicina no item VIII refere a possibilidade desta prática, desde que haja manifestação prévia. Deve-se, contudo, considerar a finalidade da reprodução assistida. Mesmo quando autorizada, a inseminação post mortem deve estar de acordo com a finalidade maior, que é a de auxiliar na resolução dos problemas de reprodução humana, facilitando o processo de procriação dentro de um projeto parental preexistente $(. . .)^{45}$.

Parece que ao considerar essencial a autorização expressa e a preexistência de um projeto parental, fica esquecida a constitucionalização do direito de família e, principalmente,

43 BBC. Mulher usa sêmen do filho morto e barriga de aluguel para se tornar avó. Disponível em <https://www.bbc.com/portuguese/geral-43162469>. Acesso em: 18 de maio de 2019.

44 PINHEIRO, Aline. Decisão que proibia mãe de engravidar com óvulo de filha morta é derrubada. Disponível em < https://www.conjur.com.br/2016-jul-04/inglaterra-permite-mae-engravide-ovulo-filhamorta>. Acesso em 18 de maio de 2019.

45 "A seleção e congelamento de óvulos da filha ocorreu para que lhe fosse permitido completar o projeto parental após tratamento agressivo da doença. O congelamento do material para utilização pela própria filha, cientificamente viável e hoje até recorrente, encontra justificativa ética na possibilidade de que os óvulos viessem a ser atingidos e o futuro projeto parental de pessoa tão jovem (ainda com 28 anos) já fosse interrompido". Assessoria de Comunicação do IBDFAM. "Justiça inglesa decide se mãe pode usar óvulos de filha morta para engravidar". <http://www.ibdfam.org.br/noticias/5920/Justi\%C3\%A7a+inglesa+decide+se+m\%C3\%A3e+pode+usar+\%C 3\%B3vulos+de+filha+morta+para+engravidar>. Acesso em: 02 Agosto 2019. 
o princípio da afetividade, que tem força para romper vínculos biológicos entre pessoas vivas e, consequentemente, por uma série de fatores, deve ser aplicado nesses casos.

Afirma-se que "na formação de uma família cada pessoa ocupa papel, uma função, na estrutura do núcleo, e que a função paterna pode ser exercida em diferentes circunstâncias, por outra pessoa que não seja o genitor ${ }^{46 "}$.

Rodrigo da Cunha Pereira ${ }^{47}$ esclarece que a função paterna pode apresentar variações, conforme propõe a psicanálise:

É essa função paterna exercida por um pai que é determinante e estruturante dos sujeitos. Portanto, o pai pode ser uma série pessoas ou personagens: o genitor, o marido da mãe, o amante oficial, o companheiro da mãe, o protetor da mulher durante a gravidez, o tio, o avô, aquele que cria criança, aquele que dá seu sobrenome, aquele que reconhece a criança legal ou almente, aquele que fez a adoção..., enfim, aquele que exerce uma função de pai.

No Brasil, um casal deixou embriões congelados em uma clínica, o genitor faleceu e após oito anos a genitora teve o desejo de ser mãe novamente. Entretanto, a clínica negou, pois o marido não deixou uma autorização sobre o que ser feito com o material. Outro exemplo, não tão recente, é de uma viúva ${ }^{48}$, que através de uma decisão liminar, conseguiu realizar a inseminação após o falecimento do esposo, mesmo sem o termo de consentimento do genitor.

Diante desses casos, observa-se que as relações humanas são mutáveis, continuamente avançam a depender da necessidade e do desejo das pessoas e também são influenciadas pelas questões culturais que as permeiam.

Como alerta Zygmunt Bauman ${ }^{49}$ :

Num mundo em que as coisas deliberadamente instáveis são a matéria-prima das identidades, que são necessariamente instáveis, é preciso estar constantemente em alerta; mas acima de tudo é preciso manter a própria flexibilidade e velocidade de reajuste em relação aos padrões cambiantes do mundo 'lá fora'.

Percebe-se que as questões envolvendo a RA, tendo em vista a ausência da sua matéria em lei e a intenção de considerar conceitos da bioética, do direito de família e dos princípios constitucionais, exigem a adoção de técnicas interpretativas rozáveis e passíveis de tutelar a pessoa humana, diante dos conflitos a serem solucionados envolvendo às demandas

46 FARIAS, Cristiano Chaves de. ROSENVALD, Nelson. Curso de Direito Civil: Famílias. Salvador: JusPodivm, 2019. p. 632.

47 PEREIRA, Rodrigo da Cunha. Direito de Família: uma abordagem psicanalítica. Rio de Janeiro: Forense, 2012. p. 126.

48 FANTÁSTICO. Viúva tem pedido negado para implantar embriões congelados dela e do marido. Disponível em: <https://g1.globo.com/fantastico/noticia/2019/04/28/viuva-tem-pedido-negado-paraimplantar-embrioes-congelados-dela-e-do-marido.ghtml>. Acesso em: 18 de maio de 2019.

49 BAUMAN, Zygmunt. Modernidade Líquida. Trad. Plínio Dentzien. Rio de Janeiro: Zahar, 2001. p. 100. 
familiaristas. "É a consideração das diferenças, e não da igualdade, que possibilitará a aproximação do ideal de justiça ${ }^{50}$.

\section{CONSIDERAÇÕES FINAIS}

A reprodução humana assistida se concentra em várias técnicas e todas elas são desafiadoras quando exigem uma interface com o direito de família constitucionalizado. A técnica denominada social freezing vem sendo cada dia mais utilizada por mulheres que desejam postergar a maternidade, mas ainda existem dúvidas quanto à utilização ou quanto ao descarte dos óvulos congelados pelos ascendentes ou outros parentes.

Considerando o tempo das famílias e as múltiplas possibilidades de formação, aliada a evolução científica e necessidades sociais, é, pois, a reprodução assistida, relevante instrumento da ciência e da medicina, que se coloca como meio viável às pessoas que não podem ter filhos, seja por razões biológicas ou não.

Diante dos inúmeros avanços da sociedade e da consequente emancipação da mulher, a reprodução humana assistida foi analisada sob a perspectiva da autonomia existencial e os desdobramentos daí advindos, perpassando pela questão da ausência de legislação específica no tratamento da matéria, já que, atualmente, o Brasil apenas faz uso da Resolução no 2.168/2017 do Conselho Federal de Medicina.

Diante da dificuldade do Estado-legislador acompanhar as revoluções tecnológicas ligadas à reprodução assistida e diante das cláusulas contratuais presentes no termo de consentimento imposto pelas clínicas, que consideram que o descarte do material seja possível, a pesquisa analisou se é ou não possível a continuidade do procedimento por meio da reprodução post mortem, considerando o princípio da intervenção mínima estatal, que possibilita a prevalência da autonomia privada, isto é, aplicar ao caso concreto a autodeterminação do indivíduo.

Acredita-se que o estudo da temática perpassa pela necessidade do Estado-Legislador e, não apenas do Estado-juiz, regular a importante e cada vez mais utilizada instrumentalização de geração de vidas por meio da reprodução assistida, porque frente a efemeridade da vida e o progresso da medicina reprodutiva, questões como a trabalhada começam a surgir e não podem ficar à mercê de julgamentos baseados em subjetivismos, instruções normativas ou resoluções.

50 PEREIRA, Rodrigo da Cunha. Direito de Família: uma abordagem psicanalítica. Rio de Janeiro: Forense, 2012. p. 151. 
Defende-se que estrutura familiar pode gerar questões complexas, que também são dinâmicas, apesar de todos os avanços que já alcançados.

Apesar de toda a construção interpretativa proposta por meio do critério metodológico da constitucionalização das relações familiares, o direito de família ainda se apresenta com viés patrimonialista, no que tange, inclusive, à possibilidade do nascimento de uma nova vida.

Não se pode esquecer que as técnicas de reprodução assistida movimentam vetores econômicos das clínicas médicas, que são estruturas empresariais constituídas, além de promoverem relevante circulação econômica ligada ao uso de medicamentes necessários para o tratamento.

O perfil consensual e o afeto devem ser considerados como alicerces das famílias, mas a análise do tema não se faz de modo simples, pois, requer a compreensão e a conjugação da responsabilidade e da ética nas relações humanas, que avançará na delimitação dos direitos da personalidade e da autonomia existencial dos atores envolvidos neste conflito, assim como possibilidades hermenêuticas construídas em torno do desenvolvimento humano como um processo integrado de liberdades interligadas.

Quanto ao problema proposto, a afetividade e o planejamento familiar foram tratados como vetores interpretativos aptos a auxiliarem na resolução da questão, quando esta chegar ao Poder Judiciário. No entanto, inúmeros outros questionamentos surgem da premissão inicial deste estudo, como a própria violação do princípio da proteção à pessoa humana, em relação aquele gameta, que evoluirá para embrião e será gerado por substituição, além de questões morais, sucessórias e patrimoniais.

\section{REFERÊNCIAS}

ANSA. Reprodução Assistida já Gerou Mais de 8 Milhões de Bebês. Disponível em $<$ https://istoe.com.br/reproducao-assistida-ja-gerou-mais-de-8-milhoes-de-bebes/>. Acesso em 18 de maio de 2019.

ANVISA/ASCON. Reprodução Humana Assistida cresce 18,7\% em 2018. Disponível em <http://portal.anvisa.gov.br/rss/-/asset_publisher/Zk4q6UQCj9Pn/content/id/5563133>. Acesso em: 17 de maio de 2019

BARBOZA, Heloisa Helena. A filiação em face da inseminação artificial e da fertilização "in vitro". Rio de Janeiro: Renovar, 1993.

Desconhecimento da paternidade do filho havido por inseminação heteróloga consentida pelo marido. Revista Trimestral de Direito Civil. a. 1, v. 1, jan./mar. 2000. 
BASSETTE, Fernanda. Brasileiras Triplicam Busca por Congelamento de Óvulos para Adiar Maternidade. Disponível em: https://www.bbc.com/portuguese/geral-45325932 . Acesso em 18 de maio de 2019.

BBC. Mulher usa sêmen do filho morto e barriga de aluguel para se tornar avó. Disponível em <https://www.bbc.com/portuguese/geral-43162469> . Acesso em: 18 de maio de 2019.

BAUMAN, Zygmunt. Modernidade líquida. Trad. Plínio Dentzien. Rio de Janeiro: Zahar, 2001.

CALDERÓN, Ricardo. Princípio da afetividade no direito de família. Rio de Janeiro: Forense, 2017.

DUQUE, Bruna Lyra. Causa do contrato: entre direitos e deveres. Belo Horizonte: Conhecimento, 2018.

Adoção, perda de uma chance e abandono estatal. Revista de Direito de Família e das Sucessões. São Paulo: RT, a. 3, n. 8, p. 67-82, abr./mai. 2016.

; LEITE, Letícia Durval. Dever fundamental de afeto e alienação parental. Revista de Direito de Família e das Sucessões, v. 3, p. 15-31, 2016.

LEITE, Letícia Durval. A alienação parental sob a perspectiva do dever fundamental de afeto e a psicologia, Revista de artigos da $1^{\mathrm{a}}$ Jornada Científica Científica do Fórum de Assistentes Sociais e Psicólogos do Poder Judiciário do ES, Vitória, p. 293-298, 2015.

SANTOS, Danilo Ribeiro Silva dos. Novas perspectivas das ações de família: a cultura do litígio perde a sua força. In: $2^{\mathrm{a}}$ Jornada Científica do Fórum de Assistentes Sociais e Psicólogos do Poder Judiciário do ES, 2017, Vitória, ES. Revista de artigos da $2^{\text {a }}$ Jornada Científica do Fórum de Assistentes Sociais e Psicólogos do Poder Judiciário do ES, Vitória, p. 254-262, 2017.

FACHIN, Luiz Edson. Da Paternidade - Relação Biológica e Afetiva. Belo Horizonte: Del Rey, 1996.

Teoria crítica do direito civil. Rio de Janeiro: Renovar, 2003.

Princípios Constitucionais do Direito de Família brasileiro contemporâneo. In:

BASTOS, Ferreira Eliene; DIAS, Maria Berenice (Coords.). A família além dos mitos. Belo Horizonte: Del Rey, 2008.

FARIAS, Cristiano Chaves de. ROSENVALD, Nelson. Curso de Direito Civil: Famílias. Salvador: JusPodivm, 2019.

GAMA, Guilherme Calmon Nogueira da. Princípios constitucionais de direito de família: guarda compartilhada à luz da lei n.o 11.698/08 - família, criança, adolescente e idoso. São Paulo: Atlas, 2008.

GIORGIO, Natalie Cafrunidi. Consequências Jurídicas de Reprodução Assistida Heteróloga. Revista da Faculdade de Direito da UFRGS, n. 33, 2015. p. 260-282.

GOZZO, Débora. Reprodução Humana Assistida e Autonomia existencial da Mulher. Disponível em <https://cadernosdoceas.ucsal.br/index.php/direitosfundamentaisealteridade/article/view/435> Acesso: 18 de maio de 2019. 
; LIGIERA, Wilson Ricardo. Maternidade de substituição e a lacuna legal: questionamentos. Civilistica.com. Rio de Janeiro, a. 5, n. 1, 2016. Disponível em: <http://civilistica.com/maternidade-de-substituicao-e-a-lacuna-legal-questionamentos/>. Acesso em: 17 de maio de 2019.

JONAS, Hans. O princípio responsabilidade: Ensaio de uma ética para a civilização tecnológica. Rio de Janeiro: Contraponto: Ed. PUC-Rio, 2006.

MADALENO, Rolf. Direito de Família. 9. Ed. Rio de Janeiro: Forense, 2019.

PAULO, Beatrice Marinho. Ser Mãe nas Novas Configurações Familiares: a Maternidade Psicoafetiva. Revista Brasileira de Direito das Famílias e Sucessões, Porto Alegre, Magister; Belo Horizonte, IBDFAM, v. 9, abr./maio 2009, p. 57.

PEREIRA, Rodrigo da Cunha. Famílias Ectogenéticas e o Contrato de Geração de Filhos. Disponível em <https://www.conjur.com.br/2018-ago-19/processo-familiar-familiasectogeneticas-contrato-geracao-filhos> Acesso em: 06 de junho de 2019.

Direito de Família: uma abordagem psicanalítica. Rio de Janeiro: Forense, 2012. Princípios fundamentais norteadores do direito de família. 2. ed. São Paulo: Saraiva, 2012.

Família, direitos humanos, psicanálise e inclusão social. Revista do Ministério Público do Rio Grande do Sul, n. 58, maio/ago., p. 195-201, 2006.

PINHEIRO, Aline. Decisão que proibia mãe de engravidar com óvulo de filha morta é derrubada. Disponível em < https://www.conjur.com.br/2016-jul-04/inglaterra-permite-maeengravide-ovulo-filha-morta>. Acesso em 18 de maio de 2019.

PONTES DE MIRANDA, Francisco Cavalcanti. Tratado de Direito de Família. Campinas: Bookseller, 2003. p. 23.

SÁ, Maria de Fátima de; TEIXEIRA, Ana Carolina Brochado. Direito de Família na Perspectiva Biojurídica. Disponível em

<http://www.fumec.br/revistas/meritum/article/view/746>. Acesso: 18 de maio de 2019.

SANTOS, Henrique Coutinho Miranda. Reprodução Assistida "Post Mortem". Disponível em <https://coutinhocarlota.jusbrasil.com.br/artigos/236655745/reproducao-assistida-postmortem>. Acesso em: 18 de maio de 2019.

SOCIEDADE BRASILEIRA DE REPRODUÇÃO ASSISTIDA. Congelamento de Óvulos é Mais Eficaz Em Mulheres de Até 35 Anos. Disponível em

$<$ https://sbra.com.br/noticias/congelamento-de-ovulos-e-mais-eficaz-em-mulheres-de-ate-35anos/>. Acesso em: 18 de maio de 2019.

STARZA-ALLEN, Antony. Birth rate up, multiple-birth rate down - egg freezing more common, says HFEA.Disponível em < https://www.bionews.org.uk/page_95458>. Acesso em: 06 de agosto de 2019.

VENTURA, Miriam. Direitos Reprodutivos no Brasil. $3^{\text {a }}$ Ed. Brasília: UNFPA, 2009. p. 256. Disponível em: < http://www.unfpa.org.br/Arquivos/direitos_reprodutivos3.pdf>.

Acesso em: 23 de agosto de 2019. 